\title{
Hospital discharge rates for suspected acute coronary syndromes between 1990 and 2000: population based analysis
}

N F Murphy, K MacIntyre, S Capewell, S Stewart, J Pell,J Chalmers, A Redpath, S Frame, J Boyd, JJ V McMurray

Although hospital discharge rates for acute myocardial infarction are falling, ${ }^{1-4}$ no contemporary studies compare temporal trends in these rates for angina and other types of chest pain. We examined recent trends in population discharge rates for myocardial infarction, angina, and chest pain ("suspected acute coronary syndromes") between 1990 and 2000.

\section{Participants, methods, and results}

We got data from the Scottish morbidity record for Scottish residents aged at least 18 years with a "first" emergency hospitalisation for myocardial infarction (codes ICD-9 (international classification of diseases, ninth revision) 410, ICD-10 I21 or I22), angina (ICD-9 411 or 413; ICD-10 I20 or I24.9) or "other chest pain" (ICD-9 786.5; ICD-10 R07), between 1990 and 2000. We analysed discharges coded only in the principal position. A "first" hospitalisation was one with no discharge diagnosis of coronary heart disease or chest pain in the previous 10 years.

We calculated rates using annual official age and sex specific population estimates for 1990-2000 and

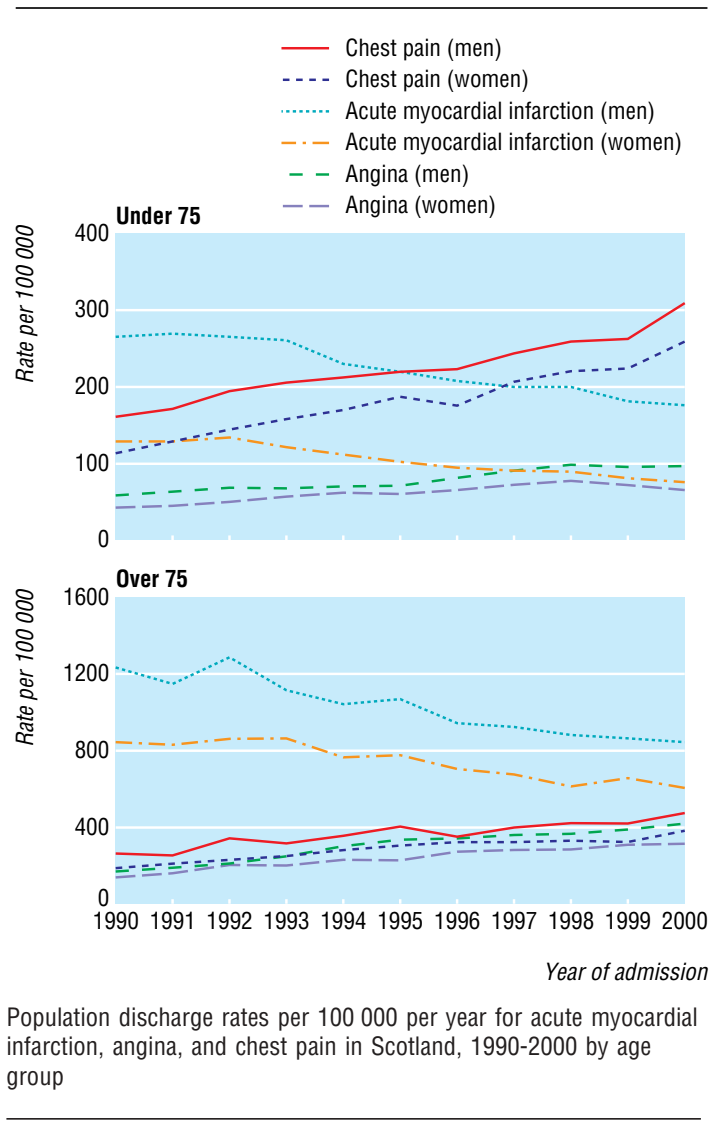

tested the significance of trends in discharge rates with linear regression.

We found 225512 first hospitalisations for suspected acute coronary syndrome with a discharge diagnosis of myocardial infarction in 96026 (43\%), angina in 37403 (17\%), and other chest pain in 92083 $(41 \%)$. Patients with angina were on average 11 years older and those with myocardial infarction 13 years older than patients with chest pain (both $\mathrm{P}<0.001$ ).

The population discharge rate for myocardial infarction fell by a third, from 260 to 173 per 100000 between 1990 and 2000 (regression coefficient (average change per year in population hospitalisation rate) $-9.9 ; 95 \%$ confidence interval -11.5 to -8.2 ). Conversely, the rate for angina increased by $79 \%$, from 59 to 105 per $100000(5.2 ; 4.3$ to 6.1$)$. The discharge rate for other chest pain increased by $110 \%$, from 114 to 296 per 100000 (coefficient 13.6; 11.6 to 15.5). The rate for myocardial infarction or angina decreased by $12 \%$, from 319 to 278 per $100000(-4.7 ;-6.6$ to $-2.7)$, though that for any suspected acute coronary syndrome increased by a quarter, from 460 to 574 per $100000(8.9 ; 6.0$ to 11.8$)$.

The greatest change, across all diagnostic subgroups, was in elderly people (figure). The decline in myocardial infarction was much greater in men than in women in young and older age groups. The increase in angina was slightly greater in men than in women in both age groups. For chest pain, the increases were comparable in men and women in both age groups.

\section{Comment}

The fall in hospitalisation rates for myocardial infarction is consistent with reports from other countries but contrasts with the rise in rates for angina and chest pain. ${ }^{1-4}$ The Minnesota heart survey, the only other study to show a rise in discharge rates for angina, reported a $56 \%$ increase in men (30\% in women) during 1985-1995 (with a 20\% decline for myocardial infarction in men and women). ${ }^{4}$ We found no similar reports of an increase in chest pain discharges.

Possible reasons for this apparent shift are increased survivorship from previous acute coronary events (unlikely given that we looked only at first admissions); a change in the clinical course of coronary heart disease (overall decline and shift from presentation with infarction to angina-for example, because of wider use of aspirin); better diagnostic exclusion of infarction; or "threshold" changes for both admission and diagnosis over the period of study.

The increase in hospitalisations for angina and chest pain has enormous implications for resources,

This article was posted on bmj.com on 21 May 2004: http://bmj.com/cgi/ doi/10.1136/bmj.38111.650741.F7
Department of

Cardiology, Western

Infirmary, Glasgow

G12 8QQ

N F Murphy

research fellow

JJ V McMurray

professor

Department of

Public Health,

University of

Glasgow, Glasgow

G12 8RZ

K MacIntyre

specialist registrar

Department of

Public Health,

University of

Liverpool,

Liverpool L69 3GB

$\mathrm{S}$ Capewell

professor

Division of Health

Sciences, University

of South Australia,

Adelaide 5000 ,

Australia

S Stewart

professor

Greater Glasgow

Health Board,

Glasgow G3 8YU

J Pell

consultant

Information and

Statistics Division,

Edinburgh

EH5 3SQ

J Chalmers

consultant

A Redpath

statistician

S Frame

principal analyst

J Boyd

record linkage project

manager

Correspondence to:

JJ V McMurray

j.mcmurray@bio.gla.ac.uk

BMJ 2004;328:1413-4 


\section{What is already known on this topic?}

Incidence of acute myocardial infarction has declined in recent years

\section{What this study adds}

Between 1990 and 2000, population hospitalisation rates for angina increased by $79 \%$, for chest pain by $110 \%$ (acute myocardial infarction declined by $33 \%$ ), and for any suspected acute coronary syndrome (myocardial infarction, angina, or chest pain) by $25 \%$

These increases have important financial and service implications

finances, and services-for example, expansion of coronary intervention for increasing angina and development of observation units for chest pain to avoid admission for non-coronary chest pain.

Contributors: NM, KM, SC, and JMcM designed the study. NM coordinated the study, analysed the data, and led the writing team. NM and KM contributed to the study desion, data analysis, and report drafting. SS, JP, JC, AR, and JB helped analyse and interpret the data and draft the report. SF contributed to the study design and extracted the data. All investigators contributed to the final report. JM, KM, and NM are guarantors. Funding: NM is funded by the British Heart Foundation, SS is supported by the National Health and Medical Research Council of Australia and the National Heart Foundation of Australia. Competing interests: None declared.

Ethical approval: Not needed.

1 Rosen M, Alfredsson L, Hammar N, Kahan T, Spetz CL, Ysberg AS. Attack rate, mortality and case fatality for acute myocardial infarction in Sweden during 1987-95: results from the national AMI register in Sweden.J Intern Med 2000;248:159-64.

2 Marques-Vidal P, Ruidavets JB, Cambou JP, Ferrieres J. Incidence, recurrence, and case fatality rates for myocardial infarction in southwestern France, 1985 to 1993 . Heart 2000;84:171-5.

3 Goldberg RJ, Yarzebski J, Lessard D, Gore JM. A two-decades (1975 to1995) long experience in the incidence, in-hospital and long-term case-fatality rates of acute myocardial infarction: a community-wide perspective. J Am Coll Cardiol 1999;33:1533-9.

4 McGovern PG, Jacobs DR Jr, Shahar E, Arnett DK, Folsom AR, Blackburn $\mathrm{H}$, et al. Trends in acute coronary heart disease mortality, morbidity, and medical care from 1985 through 1997: the Minnesota heart survey. Circulation 2001;104:19-24.

5 Kendrick S, Clarke J. The Scottish record linkage system. Health Bull (Edinb) 1993;51:72-9.

(Accepted 22 January 2004)

doi 10.1136/bmj.38111.650741.F7

\section{Northern Ireland-poetic sectarianism}

During my decade of neurosurgical experience in Northern Ireland, I became fairly used to managing patients involved in sectarian skirmishes. Most patients were young lads with a Northern Irish accent, usually victims of violent incidents like stone throwing, assaults, or even punishment beatings. The commonest type of injuries were long bone fractures,

"knee-cappings," and depressed fractures of the skull. Generally, the patients were conscious when admitted on to the neurosurgical wards. Contrary to what one would have expected, they showed hardly any of the religious hatred that would be a natural reaction, in such circumstances, anywhere else in the world. They were, surprisingly, very friendly, cooperative with the staff, and had a good sense of humour. If asked what had happened and why they were assaulted, they would promptly reply, "I didn't do nothing, dactor. Mishtaken identity."

One thing always intrigued me. Many of these patients had on their arms or chest different tattoos. These normally signified a particular political or paramilitary subgroup they were loyal to. Over the years, simply by observation, I had learnt which tattoos represented which groups. Normally the patients and the local staff hardly ever discussed religion or similar topics with each other. However, they had no such inhibitions with me and were quite ready to discuss matters freely, many lucidly expressing their perception of the troubles and invariably justifying their own choice of solutions. Probably they were confident that a doctor of Indian origin could hardly have any prejudicial interest in the Protestant-Catholic conflict.

One patient was slightly different. He had been assaulted with baseball bats and had sustained a small depressed fractured skull. As usual, he claimed to be a victim of mistaken identity and had tattoos all over the body. To my surprise, however, although all other features fitted well with a sectarian explanation for his injuries, the tattoos were quite different. They did not seem to represent any religious inclination.

I could not help being inquisitive about the meaning of the tattoos. He explained each in detail but without any religious hint. Rather than asking him directly which paramilitary subgroup he belonged to, I continued to probe obliquely: "These tattoos aren't typical; they don't really mean anything, do they?" $\mathrm{He}$ probably read my mind and understood the purpose behind the question, because he suddenly raised his right arm into the air. Slightly startled by his action, I did not know how to react. However, he kept his arm raised and made sure that I noticed the lines tattooed on the medial part of his arm, which wouldn't have been seen normally. A smile appeared on his face as I started reading the tattooed message aloud

"One Queen, One Crown

No Pope in this Town"

Both of us burst into laughter, and my knowledge of religious tattoos was enriched further.

Kishor Choudhari consultant neurosurgeon, Royal Victoria Hospital, Belfast

We welcome articles up to 600 words on topics such as A memorable patient, A paper that changed my practice, My most unfortunate mistake, or any other piece conveying instruction, pathos, or humour. Please submit the article on http://submit.bmj.com Permission is needed from the patient or a relative if an identifiable patient is referred to. We also welcome contributions for

"Endpieces," consisting of quotations of up to 80 words (but most are considerably shorter) from any source, ancient or modern, which have appealed to the reader. 